\title{
Role of Arterial Blood Gases in Determining the Treatment and Prognosis of Patients Admitted in Respiratory Intensive Care Unit (RICU)
}

\author{
B. M. Reddy ${ }^{1}$, P. Viritha ${ }^{2}$, Badusha ${ }^{3}$, V. V. R. Reddy ${ }^{4}$
}

\begin{abstract}
1Post graduate Department of Respiratory Medicine, Maharaja Institute of Medical Sciences, Vizianagaram, Andhra Pradesh, India. ${ }^{2}$ Associate professor Department of Respiratory Medicine, NRI Institute of Medical Sciences, Visakhapatnam, Andhra Pradesh, India. ${ }^{3}$ Assistant professor Department of Respiratory Medicine, NRI Institute of Medical Sciences, Visakhapatnam, Andhra Pradesh, India. ${ }^{4}$ Professor \& HOD Department of Respiratory Medicine, Maharaja Institute of Medical Sciences, Vizianagaram, Andhra Pradesh, India.
\end{abstract}

\section{ABSTRACT}

\section{BACKGROUND}

It is well known that various ABD are very common in critical illness. Prompt correction of $\mathrm{ABD}$ and treating the underlying cause as soon as possible is the key to reduce morbidity and mortality. Although ABDs are quite common in the respiratory ICU and are generally associated with significant morbidity and mortality, the precise incidence and prevalence of ABDs have not been fully determined in patients presenting at the respiratory ICU. Many of the studies that have been conducted on this topic have included critical patients in multidisciplinary intensive care units and emergency departments but there are no studies particularly in Respiratory ICU. The current study was planned with an objective of assessing the pattern of ABG with severity and prognosis of disease in RICU.

\section{METHODS}

In this prospective observational study, all patients admitted in RICU of the Maharajah's Institute of Medical Sciences between January 2016 and August 2017 for a period of 18 months were included and subjected to ABG sampling.

\section{RESULTS}

All ABD types were most commonly observed in patients over 60 years of age. In cases of ABD, COPD, Pneumonia was the most common diagnosis (26\%). The most common ABD seen in COPD is RAC + MAL (86.9\%) and the most common ABD seen in pneumonia is MAC + RAL (52.1\%). Of the 100 cases with an ABD, 27 patients (27\%) had simple ABD and 73 patients $(73 \%)$ had mixed ABD. The most common ABD was a mixed respiratory acidosis and metabolic alkalosis (RACMAL) $(n=37$, $37 \%)$.

\section{CONCLUSIONS}

Acid-base disorders are common in patients presenting at the ED, especially among very sick patients. Thus, ABGs should definitely be evaluated in the management of such patients. Of the ABDs RAC + MAL and MAC + RAL is the most common. Respiratory acidosis was more common among SABD cases. All types of acid-base disorders are observed primarily in patients over 65 years of age.

\section{KEY WORDS}

ABD, SABD, MABD, RAC, RAL, MAC, MAL
Corresponding Author: Dr. Pandu Viritha,

D. No. 3-52, Netaji Nagar, Old Dairy Farm, Visakhapatnam-530040,

Andhra Pradesh, India.

E-mail: viritha_doc@yahoo.co.in

DOI: $10.14260 /$ jemds/2019/719

Financial or Other Competing Interests: None.

How to Cite This Article:

Reddy BM, Viritha P, Badusha, et al. Role of arterial blood gases in determining the treatment and prognosis of patients admitted in respiratory intensive care unit (RICU). J. Evolution Med. Dent. Sci. 2019;8 (44):3314-3317, DOI: 10.14260/jemds/2019/719

Submission 18-04-2019, Peer Review 20-10-2019, Acceptance 26-10-2019, Published 04-11-2019. 


\section{BACKGROUND}

Acid-base homeostasis is crucial to the normal function of body. If acid-base disorder (ABD) is not detected timely, it may lead to serious or potentially fatal conditions. Arterial blood gas (ABG) testing is widely used in RICU to evaluate metabolic and respiratory functions $\left(\mathrm{PaCO}_{2}, \mathrm{PH}\right.$ and $\left.\mathrm{PaO}_{2}\right)$. In addition, this test can help to guide the diagnosis and treatment of many patients and can offer details concerning the severity of a case. ${ }^{1}$ It is usually correlated with high rates of morbidity and mortality. ${ }^{2}$ The types, causes, treatments and outcomes of ABD inpatients presenting at the RICU have not been extensively reported. In general, it is difficult to make the diagnosis of $\mathrm{ABD}$, fully understand the complications associated with it and its impact on organ function. ABD should be suspected in every patient with abnormal vital signs. The four main types of ABDs (respiratory and metabolic acidosis, respiratory and metabolic alkalosis) are described as simple ABD, while having two or more simple ABDs together is defined as mixed ABD. ${ }^{3}$ Disturbances of the acid-base equilibrium occur in a wide variety of critical illnesses and are among the most commonly encountered disorders in the ICU. In addition to reflecting the seriousness of the underlying disease, these disorders have their own morbidity and mortality. Normal Acid-Base homeostasis System arterial PH is maintained between 7.35 and 7.45 by extracellular and intracellular buffering together with respiratory and renal regulatory mechanisms. Control of $\mathrm{PaCO}_{2}$ by CNS and respiratory system and control of plasma $\mathrm{HCO}_{3}$ by kidneys stabilize the arterial $\mathrm{PH}$. Kidneys filter $4000 \mathrm{mmol}$ of $\mathrm{HCO}_{3}$ per day and renal tubules secrete equal amount of $\mathrm{H}^{+}$and absorb this $\mathrm{HCO}_{3}$. 80$90 \%$ of bicarbonate is reabsorbed in the proximal tubule. The magnitude of this process is modulated by the state of ECF volume, Serum $\mathrm{K}+$ and $\mathrm{PCO}_{2}$. The distal nephron secretes protons $\left(\mathrm{NH}_{4}{ }^{+}\right.$and titratable acid) generated by metabolism amounting 40-60 mmol/dl. Major means of net $\mathrm{H}^{+}$excretion is renal ammonia genesis. $\mathrm{Net}^{+}$excretion take place in the distal tubule where it is used to titrate $\mathrm{NH}_{3}$ and $\mathrm{HPO}_{4}-2$. The major role of the lungs in acid base balance are to excrete the $\mathrm{CO}_{2}$ produced daily by aerobic metabolism and to compensate for primary metabolic acid base disturbance by altering the rate and depth of ventilation. Majority of the $\mathrm{CO}_{2}$ generated by tissues is carried within RBC whereby carbonic anhydrase turns into carbonic acid which disassociate to $\mathrm{H}^{+}$ and $\mathrm{HCO}_{3}$. The $\mathrm{H}^{+}$is buffered by haemoglobin at low oxygen tension in the venous blood. The $\mathrm{HCO}_{3}$ - leaves the cell in exchange with $\mathrm{CL}$ - leading to increased $\mathrm{HCO}_{3}$ - in the blood. In pulmonary circulation the enhanced oxygenation of haemoglobin releases $\mathrm{H}^{+}$. The $\mathrm{H}^{+}$and $\mathrm{HCO}_{3}$ - via carbonic anhydrase continue to reform $\mathrm{CO}_{2}$, which passively diffuses from the blood into the pulmonary interstitium where the $\mathrm{CO}_{2}$ tension is very low. Subsequently $\mathrm{CO}_{2}$ is lost into the alveolar space.

\section{METHODS}

In this prospective observational study, we included adult patients presenting at the RICU of the Maharaja Institute of
Medical Sciences between January 2016 and August 2017. A total of 100 patients selected using convenient sampling technique presented with various complaints were enrolled in the study. Exclusion criteria are as follows: those patients who died on or before arrival; those who were transferred out of critical care area within two hours of arrival; patients with "Do Not Resuscitate" orders; trauma patients, those with missing data, and inappropriate blood gas samples. Age, gender, primary disease, underlying problems, complications, duration of stay in RICU, treatment given, and outcome were collected. ABG samples were collected immediately after presentation to the RICU. Adult patients who required ABG on the basis of their clinical condition were included in the study. ABG samples were taken from the femoral or radial artery. The samples were collected in heparinized syringes, and the Tests were run on the blood gas analyser GEM PREMIER 3500. Serum electrolytes were done by the method flame photometry.

Analysis of the ABG included $\mathrm{pH}$ values, the partial pressure of arterial carbon dioxide $\left(\mathrm{PaCO}_{2}\right)$, partial pressure of the arterial oxygen $\left(\mathrm{PaO}_{2}\right)$, bicarbonate $\left(\mathrm{HCO}_{3}\right)$, and the anion gap (AG). The $\mathrm{pH}$ values of 7.35-7.45 and $\mathrm{ABG}$ values, including $\mathrm{PaO}_{2}$ 80-100 mmHg, $\mathrm{PaCO}_{2}$ : 35.0-45.0 $\mathrm{mmHg} \mathrm{HCO}_{3}$ : 22.0-26.0 mEq/L, and $A G=12 \pm 4 \mathrm{mEq} / \mathrm{L}$ were considered to be within normal ranges. A $\mathrm{pH}<7.35$ combined with an increase in $\mathrm{PaCO}_{2}(>45)$ or a decrease in $\mathrm{HCO}_{3}(<22)$ is defined as either respiratory or metabolic acidosis, respectively. A pH >7.45 combined with a decrease in $\mathrm{PaCO}_{2}$ $(<35)$ or an increase in $\mathrm{HCO}_{3}(>26)$ is defined as respiratory or metabolic alkalosis, respectively. Accordingly, ABD was divided into eight groups: respiratory or metabolic acidosis, respiratory or metabolic alkalosis and mixed metabolic Respiratory acidosis (MACRAC), Metabolic Respiratory Alkalosis (MALRAL), Metabolic Acidosis Respiratory Alkalosis (MACRAL), Mixed Metabolic Alkalosis Respiratory Acidosis (MALRAC).

\section{RESULTS}

Out of 100 patients, 49 patients were treated medically, 22 patients were treated by NIV \& 29 patients were managed by IMV. Most common ABD in medically managed cases is RAC + MAL (12 out of $49,24.5 \%$ ) and most common aetiology is pneumonia (15 out of 49 cases, 30.1\%). Patients who are managed medically show good prognosis (47 out of 49 patients discharged in good condition). Patients with RAC survived \& shows good prognosis when treated with IMV.

\begin{tabular}{|c|c|c|}
\hline Type of ABD & Number & Percentage \\
\hline RAL & 05 & $5 \%$ \\
\hline MAL & 08 & $8 \%$ \\
\hline RAC & 13 & $13 \%$ \\
\hline MAC & 01 & $1 \%$ \\
\hline RAL + MAL & 06 & $6 \%$ \\
\hline MAC + MAL & 37 & $37 \%$ \\
\hline RAC + RAL & 13 & $13 \%$ \\
\hline MAC + MAL & 08 & $8 \%$ \\
\hline RAC + MAC + MAL & 01 & $1 \%$ \\
\hline MAC + RAL + MAL & 03 & $3 \%$ \\
\hline \multicolumn{2}{|c|}{ Table 1. Types of ABD'S in the Study Group with \% } \\
\hline
\end{tabular}




\begin{tabular}{|c|c|c|}
\hline Type of Disease & Number & Percentage \\
\hline COPD & 26 & $26 \%$ \\
\hline Pneumonia & 26 & $26 \%$ \\
\hline ARDS & 06 & $06 \%$ \\
\hline ILD & 08 & $08 \%$ \\
\hline Cardiogenic pulmonary oedema & 04 & $04 \%$ \\
\hline Pneumothorax \&hydropneumothorax & 06 & $06 \%$ \\
\hline Pleural effusion & 06 & $06 \%$ \\
\hline Empyema & 04 & $04 \%$ \\
\hline Pleural \& parenchymal fibrosis & 04 & $04 \%$ \\
\hline Pjp pneumonia & 01 & $01 \%$ \\
\hline Pulmonary tuberculosis & 01 & $01 \%$ \\
\hline Bronchial asthma & 03 & $03 \%$ \\
\hline Kyphoscoliosis & 01 & $01 \%$ \\
\hline Obesity hypoventilation syndrome & 02 & $02 \%$ \\
\hline Bronchiectasis & 02 & $02 \%$ \\
\hline Table 2. Various Types of Respiratory Diseases with Percentage \\
\hline \multicolumn{2}{|l}{}
\end{tabular}

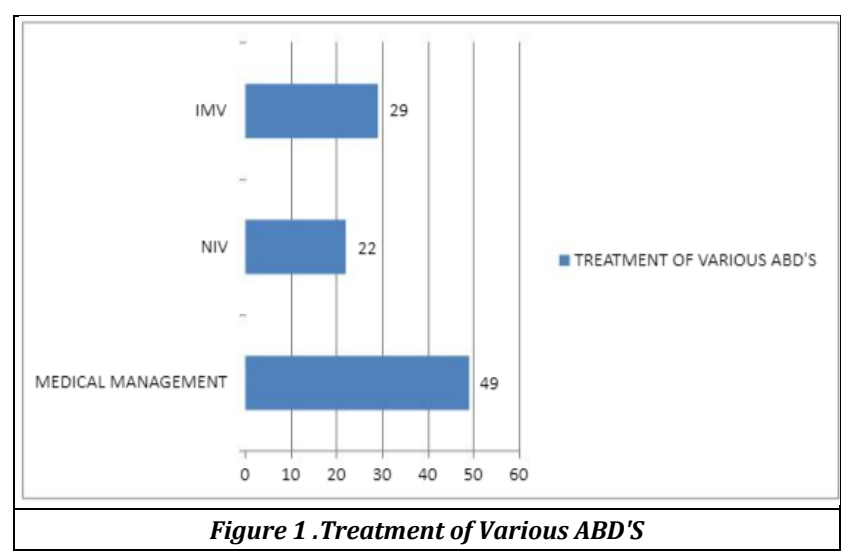

\begin{tabular}{|c|c|c|}
\hline $\begin{array}{c}\text { Outcome of Medically } \\
\text { Managed Cases }\end{array}$ & Type of ABD & Type of Disease \\
\hline & RAC + MAL (12) & COPD (5) \\
& MAL (8) & CPE (2) \\
& RAC (7) & Pnonia (14) \\
RAL + MAL (6) & Hydropneumothorax (5) \\
Survived (47) & MAC + RAL (7) & Pleural Effusion (6) Empyema \\
& & (2) Bronchiectasis (2) Fibrosis \\
& RAL (5) & $(4)$ \\
& MAC + RAL + MAL (1) & ILD (3) \\
& MAC + MAL (1) & BJP (1) \\
& MAC + RAL (1) & CPE (1) \\
\hline \multicolumn{2}{|c|}{ Table 3. Outcome of Medical Management Cases } \\
\hline \multicolumn{2}{|c|}{ Tied (2) } & \multicolumn{2}{|c|}{}
\end{tabular}

\begin{tabular}{|c|c|c|}
\hline Outcome of IMV & Type of ABD & Type of Disease \\
\hline & RAC + MAL (3) & COPD (2) \\
Survived (5) & RAC + MAC (1) MAC + RAL & Pneumonia (2) ILD (1) \\
\hline & RAC + MAC (7) & Pneumonia (9) \\
& RAC + MAL (5) & ARDS (5) \\
Died (24) & MAC + RAL (4) & COPD (5) \\
& MAC + RAL + MAL (4) & Empyema (2) ILD (1) \\
& RAC + MAC + MAL (2) & Pneumothorax (1) \\
& RAC (2) & BR. Asthma (1) \\
\hline \multicolumn{2}{|c}{ Table 4. Outcome, ABD'S and Aetiologies Associated with IMV } \\
\hline
\end{tabular}

\begin{tabular}{|c|c|c|c|}
\hline Type of Disorder & \begin{tabular}{|c|}
$\begin{array}{c}\text { Total Number of } \\
\text { Cases }\end{array}$ \\
\end{tabular} & \begin{tabular}{|c|}
$\begin{array}{c}\text { Total Number of } \\
\text { Deaths }\end{array}$ \\
\end{tabular} & $\begin{array}{c}\text { Death } \\
\text { Percentage }\end{array}$ \\
\hline $\mathrm{RAC}+\mathrm{MAC}$ & 8 & 7 & $87.5 \%$ \\
\hline RAC + MAL & 37 & 7 & $8.9 \%$ \\
\hline MAC + RAL & 13 & 5 & $38.4 \%$ \\
\hline $\mathrm{MAC}+\mathrm{RAL}+\mathrm{MAL}$ & 5 & 4 & $80 \%$ \\
\hline $\mathrm{RAC}+\mathrm{MAC}+\mathrm{MAL}$ & 3 & 3 & $100 \%$ \\
\hline RAC & 13 & 3 & $23 \%$ \\
\hline MAC & 1 & 1 & $100 \%$ \\
\hline \multicolumn{4}{|c|}{ Table 5. Percentage of Deaths in Specific Types of Disorders } \\
\hline $\begin{array}{l}\text { componen } \\
\text { losis. }\end{array}$ & (1) & $A$ & poor \\
\hline
\end{tabular}

Most common ABD associated with death when treated with IMV is RAC + MAC \& RAC + MAC + MAL (9 out of 24, $37.5 \%$ ) died. ARDS \& Pneumonia are the most common diseases that were expired during treatment with IMV (14 out of $24,58.3 \%$ ).

\section{DISCUSSION}

Although ABDs are quite common in the respiratory ICU and are generally associated with significant morbidity and mortality, the precise incidence and prevalence of ABDs have not been fully determined in patients presenting at the respiratory ICU. Many of the studies that have been conducted on this topic have included critical patients in multidisciplinary intensive care units and emergency departments but there are no studies particularly in Respiratory ICU. ABDs were more common in males. In present study $69 \%$ were males and $31 \%$ were females. $36 \%$ of patients above 60 years, of these $66.6 \%$ were males and $33.3 \%$ were females. In the present study, 27\% (n=27) of ABD patients were defined as SABD and 73\% ( $n=73)$ were characterized as MABD. Of the cases with SABD, RAC ( $n=13$, $48.1 \%$ ) is the most common ABD, while mixed RACMAL $(n=37,50 \%)$ was found to be the most common MABD.

In the present study, it was found that MAC was a stronger predictor of mortality as compared to RAC, 7 out of 8 patients $(87.5 \%)$ with MAC + RAC died whereas in RAC + MAL only 7 out of $37(8.9 \%)$ only died. It is observed that Acidosis with low bicarbonate levels (between $10-20$ meq/ l) is associated with higher hospital stay and mortality rate. In Ucgun I et $\mathrm{al}^{4}$ study in 2008, when patients were divided into two groups according to the $\mathrm{HCO}_{3}$ levels, the mortality rate was $59.1 \%$ in the group of low $\mathrm{HCO}_{3}$ and $19.8 \%$ in the group of high $\mathrm{HCO}_{3}$. In addition, only MAC was an independent predictor of mortality. This substantiates the fact that presence of MAC is an indicator of poor outcome, as Compared to RAC. MAC actually is a reflection of nonpulmonary organ dysfunction such as Circulatory failure or renal failure, whereas RAC depicts hypercapnia, pulmonary organ failure. It has also been shown that mortality increases remarkably with development of associated organ dysfunctions in presence of respiratory failure. In patients with COPD exacerbation and hypercapnia, the development of sufficient metabolic compensation and adequate renal function significantly decreases mortality. Marcun $\mathrm{R}$ et $\mathrm{al}^{5}$ in 2012 reported that COPD is a complex lung and systemic Disease that is associated with a variety of cardiovascular diseases including Coronary artery disease, peripheral vascular and cerebrovascular disease. COPD patients have frequent right and left ventricular dysfunction and an increase in sympathetic activation with high morbidity from arrhythmias. Acute exacerbations of COPD may trigger cardiac events but are also often precipitated by cardiac events. Finally, the association between lung inflammation (Including that in COPD and AECOPD) and cardiac events may be due to consequences of the systemic Inflammatory response.

Pharmacologic therapy centers on Inhaled bronchodilators, low-flow supplemental oxygen, antibiotics, and systemic corticosteroids. For severe exacerbations characterized by respiratory acidosis and hypercapnia, NPPV decreases the need for intubation, reduces infectious 
complications, and increases survival. For intubated patients there are effective strategies to improve patient ventilator interaction and reduce the adverse consequences of PEEPi. Although intubated patients have the worst prognosis, the vast majority of them can be successfully weaned from mechanical ventilation. The treatment for ABD is based on treating the underlying cause and possibly restoring the $\mathrm{PH}$ balance to physiological levels. The Acute Respiratory Distress Syndrome Network in $2000^{6}$ suggests that in patients with acute lung injury and the acute respiratory distress syndrome, mechanical ventilation with a lower tidal volume of $6-8 \mathrm{ml} / \mathrm{kg}$ is traditionally used which resulted in decreased mortality and increases the number of days without ventilator use.

In the present study Hyperlactatemia seen in 15 patients. Out of $15,12(80 \%)$ died which indicates high risk for mortality. Elevated Anion Gap seen in 25 patients, out of 25, $17(68 \%)$ died, indicates high risk for mortality. So, Hyperlactatemia (>5 mmol/L) and increased anion gap (> 15) are independent risk factors for mortality. In our study deaths were recorded more in the patients with lactate levels between 5.02-7.24 mmol/l and with an anionic gap between 20-45. Bicarbonate therapy is not useful in acute metabolic acidosis; it is useful only in chronic renal failure with bicarbonate loses. So it is not used in our study to treat metabolic acidosis patients as it worsens the patient condition by increase in $\mathrm{CO}_{2}$ production, because of its metabolism to $\mathrm{H} 2 \mathrm{O}$ and $\mathrm{CO}_{2}$ Causing respiratory acidosis. In the present study patients with pneumothorax, pleural effusion, and Empyema are treated with intercostal tube insertion and drainage. The ABG values return to its baseline value after treating primary pathology responsible for those conditions. Bayduret $\mathrm{al}^{7}$ in 2007 formulated those patients with the latter form of Disease (e.g. Idiopathic pulmonary fibrosis) has the worst prognosis and succumbs to their illness within 5 years of diagnosis. Those with a predominantly cellular component (Nonspecific Interstitial Pneumonia) respond variably to immunomodulatory therapy and either recover completely or at least have improved quality of life with a slower decline in lung function, unless they also have a fibrotic component to the disease. In our study, terminally ill ILD patients presented with SOB due to mixed ventilator defect (Both obstructive and restrictive). We treated them with $\mathrm{O}_{2}$ supplementation, parenteral steroids, steroid sparing immunosuppressive agents, NIV and IMV if necessary. Most common ABD in ILD is RAC + MAL (6 out of $8,75 \%$ ) due to hypoventilation. In our study we treated OHS, kyphoscoliosis patients with NIV which are basically restrictive ventilatory defects. The common ABD is RAC + MAL (3 out of 3, 100\%). All patents were discharged healthy after medical management and NIV. In our study triple acid base disorders constitute (8 out of 100, 8\%). Pneumonia, ARDS and COPD are commonly associated with triple disorders. Out of 8 cases 7 (87.5\%) died indicating poor prognosis of patients with triple disorders.

\section{CONCLUSIONS}

Acid-base disorders are common in patients presenting to the RICU, especially among very sick patients. Thus, ABGs should definitely be evaluated in the management of such patients the most common ABD seen in COPD is RAC + MAL and the most common ABD seen in pneumonia is MAC + RAL. The most common ABD was a RAC + MAL. $(n=37,37 \%)$. The most common ABD managed medically is RAC + MAL (28.1\%). The most common ABD which showed good prognosis and discharged in good condition is RAC + MAL ( $n=40,40 \%)$. Death was more commonly observed in cases with mixed metabolic and respiratory acidosis (MAC + RAC) and (n=7, $87.5 \%)$. Out of 30 deaths, 20 cases $(66.6 \%)$ had metabolic acidosis component. Patients with elevated anion gap and with elevated lactate levels are independent risk factors for mortality.

\section{REFERENCES}

[1] Austin K, Jones P. Accuracy of interpretation of arterial blood gases by emergency medicine doctors. Emerg Med Australas, 22, 2010, 159-65.

[2] Kelly AM. Review article: Can venous blood gas analysis replace arterial in emergency medical care. Emerg Med Australas 22, 2010, 493-8.

[3] Walmsley RN, White GH. Mixed acid-base disorders.ClinChem, 31, 1985, and 321-5.

[4] Ucgun I, Oztuna F, Dagli CE, Yildirim H, Bal C. Relationship of metabolic alkalosis, azotaemia and morbidity in patients with chronic obstructive pulmonary disease and hypercapnia. Respiration 2008; 76: $270-4$.

[5] Cheryl R. Laratta1,2 and Stephan van Eeden2,3 Biomed Res Int. 2014; 2014: Acute Exacerbation of Chronic Obstructive Pulmonary Disease: Cardiovascular Links.

[6] Ventilation with Lower Tidal Volumes as Compared with Traditional Tidal Volumes for Acute Lung Injury and the Acute Respiratory Distress Syndrome The Acute Respiratory Distress Syndrome Network N Engl J Med 2000; 342:1301-1308.

[7] Martinez FJ, Safrin S, Weycker D, Starko KM, Bradford WZ, King TE Jr, Flaherty KR, Schwartz DA, Noble PW, Raghu G, et al. The clinical course of patients with idiopathic pulmonary fibrosis. Ann Intern Med 2005;142:963-967. 